\title{
Effect of Posterior Bite Raiser on Periodontium of Lower Molars in Orthodontic Patients
}

\author{
Arya S. Prasad ${ }^{1}$, Arvind Sivakumar ${ }^{2}$ \\ 1,2 Department of Orthodontics and Dentofacial Orthopaedics, Saveetha Dental \\ College and Hospitals, Saveetha University, SIMATS, Chennai, Tamil Nadu, India.
}

\section{ABSTRACT}

\section{BACKGROUND}

Temporary bite opening with occlusal composite is performed routinely during orthodontic treatment of patients with deep bite and cross bite. There have been no studies yet to assess its effect on periodontium. This study was done to assess the effect of temporary bite-raising on periodontium when placed on the mandibular molars.

\section{METHODS}

A prospective clinical trial which was a pilot study conducted on fifteen subjects attending the Department of Orthodontics, Saveetha Dental College and Hospitals, (SIMATS), Chennai. Probing depth and pain score on percussion were recorded bilaterally on subjects with class 1 malocclusion, before and after placing bite blocks in the posterior teeth. The bite-raising was done using light cured orthodontic composite Blu Bite ${ }^{\mathrm{TM}}$ on both mandibular first molars. Probing depth was measured using a Williams probe at mesiobuccal, mid-buccal and distobuccal sites on molars and pain score on percussion was recorded using visual analogue scale. The pocket probing, before (T0) and after one month of temporary bite-raising (T1) was recorded and statistically analysed using paired $t$ test and Wilcoxon sign rank test based on normality of variables.

\section{RESULTS}

There was a significant increase in the mean probing depth after bite raising with a mean difference of $1.07 \pm 0.04(\mathrm{P}=0.000)$. The mean pain score also significantly increased after temporary bite-raising $(\mathrm{P}=0.002)$.

\section{CONCLUSIONS}

There were minor yet significant changes in the periodontium that occurred after temporary bite rising with Blu Bite ${ }^{\mathrm{TM}}$.

\section{KEY WORDS}

Composite Resin, Periodontium, Occlusal Force, Orthodontic Adhesive, Visual Analogue Pain Scale
Corresponding Author: Dr. Arya S. Prasad Qtr. No. 1/1, K. M. Raju Enclave, New RBI Complex, Near RBI, Chennai - 600001, Tamil Nadu, India. E-mail: aryasprasad7@gmail.com

DOI: $10.14260 / \mathrm{jemds} / 2021 / 363$

How to Cite This Article: Prasad AS, Sivakumar A. Effect of posterior bite raiser on periodontium of lower molars in orthodontic patients. J Evolution Med Dent Sci 2021;10(23):1756-1759, DOI: $10.14260 /$ jemds/2021/363

Submission 17-07-2020,

Peer Review 10-04-2021,

Acceptance 22-04-2021,

Published 07-06-2021.

Copyright (C) 2021 Arya S. Prasad et al. This is an open access article distributed under Creative Commons Attribution License [Attribution 4.0 International (CC BY 4.0)] 


\section{BACKGROUND}

Bite raising or bite opening is usually done in orthodontic patients undergoing orthodontic treatment for deep bite, cross bite, scissor bite, centric relation - centric occlusion discrepancies, and deprogramming the masticatory muscles. Bite opening helps in eliminating the occlusal interference thereby helps in bonding of the brackets in both the arches at the same time and permits unobstructed tooth movement. ${ }^{1}$ They are commonly referred as 'bite planes', 'bite turbos', bite plates', 'bite blocks', 'bite ramps', 'build-ups' etc. They can be made with acrylic, metal, Glass ionomer cements or composite restorations. The bite planes can be used in anterior or posterior regions depending on the type of malocclusion correction.

The mandibular plane angle plays an important role in choosing the site of bite block locations - in low angle cases anterior bite turbos are indicated and in average angle cases posterior bite turbos are indicated. ${ }^{2}$

For bite raising, numerous techniques are there like removable acrylic bite blocks, glass ionomer cements, and light cured composites. ${ }^{3}$ The bite plates used for bite opening can also be used as diagnostic appliances for bringing the mandible to its centric relation in case of functional shift and they can also be used to reduce the mobility of tooth caused due to trauma from occlusion. ${ }^{4}$

There are two types of bite planes - removable bite planes and fixed bite planes. In comparison to removable bite planes, fixed composite bite blocks are hygienic, less bulky, reduces speech interference, easy to place on the tooth surfaces without lab fabrication, do not encroach the tongue space \& do not rely on patient's compliance. ${ }^{5,6}$

It has been recently reported that bite-raising for posterior teeth using this method is an effective alternative treatment option for anterior open bite in adult patients. ${ }^{7}$ Bite opening using this method was found to be effective in mixed dentition for the correction of anterior crossbite. ${ }^{8}$ Bite raising done by using a light-cured composite on the occlusal surfaces of the posterior molars or lingual surfaces of the anterior teeth are more convenient and patient friendly than removable bite blocks. ${ }^{9,10}$

Previous studies have been done on light cured orthodontic band regarding the hyperactivity of the jaw muscles (masseter and anterior temporalis) and on masticatory function.5,10 Since they keep the functional occlusion away, they tend to have axial loading of occlusal forces that can have an effect on the masticatory system. ${ }^{11}$

Common side effects of bite blocks include difficulty in chewing, speech difficulties (lisping), risk of dental caries, soft tissue irritation etc. ${ }^{2,12}$ Also, long time wear of bite blocks is said to cause intrusion of molars. ${ }^{13}$ However there is limited evidence on the effect of increased occlusal jaw opening using light-cured orthodontic band cement on periodontium in orthodontic patients. Blu Bite ${ }^{\mathrm{TM}}$, (Anabond Stedman Pharma Research Pvt Ltd, India) is one such light cure radiopaque composite for bite raising. Thus, this prospective study was designed with an intention to examine the effect of bite opening by Blu Bite ${ }^{\mathrm{TM}}$, (Anabond Stedman Pharma Research Pvt Ltd, India) a light cure composite on the periodontium when placed onto the mandibular molars.

\section{METHODS}

A prospective clinical trial which was a pilot study done on thirty-one orthodontic patients who reported to the Department of Orthodontics and Dentofacial Orthopaedics of Saveetha Dental College and Hospitals, (SIMATS), Chennai. from October 2017 to November 2017. The inclusion criteria were orthodontic adult patients between the age of 18 and 35 years (18 years \pm 1 month) who required disocclusion using Blu Bite ${ }^{\mathrm{TM}}$ on the mandibular permanent first molar during the orthodontic treatment. All the subjects had Class I malocclusion, neither had any previous orthodontic treatment in the past nor had any other dental treatment during the study period.

Patients who were periodontally compromised, having restorations, having habits like smoking, tobacco chewing, parafunctional habits like bruxism and systemically compromised patients were excluded from this study.

Twenty-six patients were selected based on the random sampling technique. All these subjects were in the age range of 18 - 35 years irrespective of the sex and required raising the bite as a part of orthodontic treatment for correction of malocclusion. Eleven patients were excluded as they had poor oral hygiene. Finally, fifteen patients were selected for the study which included eight males and seven females. The study protocol was approved by the Institutional Review Board, Saveetha Dental College, Chennai, Tamil Nadu. Informed consent of all the participants were taken before the study.

Bites of the participants were temporarily raised by placing Blu Bite ${ }^{\mathrm{TM}}$ onto the mandibular first molars bilaterally using the following protocol. After polishing the occlusal surface, acid etching was done for 15 - 20 seconds, followed by thoroughly rinsing the surface with water and air dried, a layer of bonding agent was applied onto the tooth surfaces, Blu Bite $^{\mathrm{TM}}$ was placed on the mandibular first molars.

A light cure unit with an intensity of $3000 \mathrm{mw} / \mathrm{CM} 2$ was used to cure the composite for 30 seconds. The occlusal contacts on the molars were balanced by identifying high points on each side with an articulating film of 25 - micron thickness and high points were removed to achieve equal bilateral contact in the first molars. The mean overbite after temporary bite-raising was $1.75 \pm 0.70 \mathrm{~mm}$.

\section{Measurement of Probing Depth}

The probing depths of the mandibular first molars were measured using the Williams probe at the mesiobuccal, distobuccal and mid-buccal sites of mandibular first molars. The periodontal status of the mandibular first molars were measured in all the patients at two stages, one before Blu Bite $^{\mathrm{TM}}$ placement (T0) and another after one month (T1) of the Blu Bite ${ }^{\mathrm{TM}}$ placement.

\section{Measurement of Pain}

Pain on percussion was recorded using visual analogue scale before and after one month of Blu Bite ${ }^{\mathrm{TM}}$ placement on lower first molars. (Figure 1) 14-16 


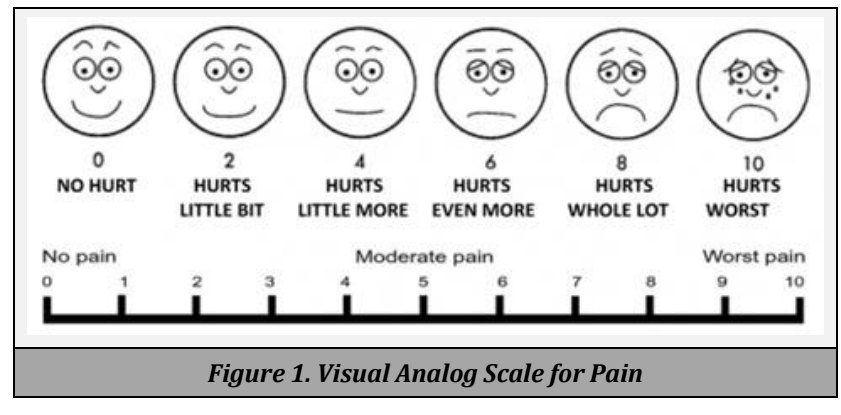

\section{Statistical Analysis}

Statistical analysis was performed using SPSS software version V21.0.0 (IBM Corporation, USA, 2012). The normality of the variables was verified by graphical method (Histogram with normal curve). Probing depth was found to be normally distributed and pain score was not found to be normally distributed. Based on the normality test, a paired t test was performed to compare the means of probing depth and a Wilcoxon signed rank test was performed to compare the median of pain scores. $\mathrm{P}$ value $\leq 0.05$ was considered to be significant.

\section{RESULTS}

The study conducted on fifteen participants with an age range of 18 - 25 years were included in the study after satisfying the selection criteria. Of the consented fifteen patients, eight were males and seven were females. The participants were dentate with Class I occlusion, an overjet of less than $3 \mathrm{~mm}$, and an overbite of less than $3 \mathrm{~mm}$ (mean overbite $2.63 \pm 0.72 \mathrm{~mm}$, mean \pm S.D).

\begin{tabular}{|c|c|c|c|c|c|c|}
\hline & \multicolumn{2}{|c|}{$\begin{array}{c}\text { Before } \\
\text { Temporary } \\
\text { Bite-Raising }\end{array}$} & \multicolumn{2}{|c|}{$\begin{array}{c}\text { After } \\
\text { Temporary } \\
\text { Bite-Raising }\end{array}$} & \multirow{2}{*}{$\begin{array}{c}\text { Mean } \\
\text { Difference } \\
\text { (95\% CI) }\end{array}$} & \multirow[t]{2}{*}{$\begin{array}{c}P \\
\text { Value }\end{array}$} \\
\hline & Mean & S.D. & Mean & S.D. & & \\
\hline $\begin{array}{l}\text { Probing } \\
\text { depth }\end{array}$ & 1.73 & 0.458 & 2.80 & 0.414 & $\begin{array}{c}-1.07(- \\
0.924 \text { to }- \\
1.210)\end{array}$ & $0.000^{*}$ \\
\hline \multicolumn{7}{|c|}{ Table 1. Periodontal Depth before and after Bite-Raising } \\
\hline
\end{tabular}

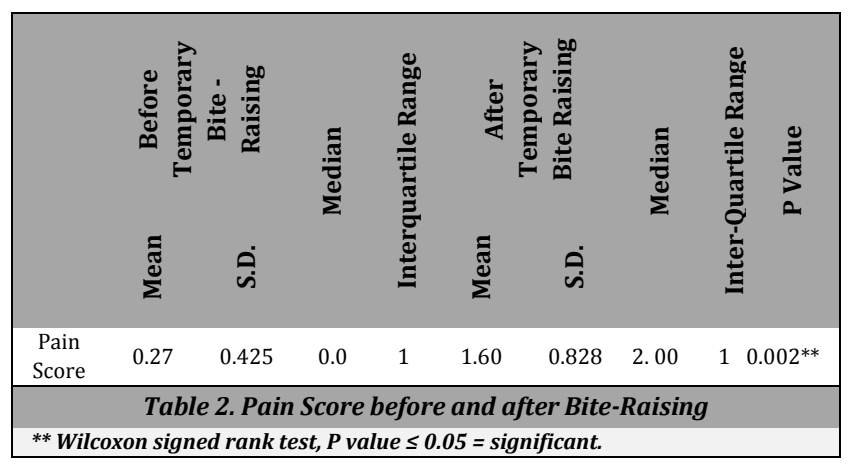

The mean probing depth before bite-raising was $1.73 \pm$ 0.458 . Similarly, the mean probing depth after bite raising was $2.80 \pm 0.414$. The mean difference $(-1.07)$ between the probing depth was found to be statistically significant with a $P$ value of 0.000 (Table 1) (Figure 2).

The mean pain score measured using visual analogue scale before bite-raising was $0.27 \pm 0.425$ (mean \pm SD). Mean pain score after bite-raising was $1.60 \pm 0.828$ (mean \pm SD). There was a statistically significant difference in the mean pain score based on negative ranks with a $\mathrm{P}$ value of 0.002 (Table 2) (Figure 3).

\section{DISCUSSION}

The study investigated the effect of temporary bite-raising with Blu Bite on the periodontium of mandibular first molars after one month of its placement. All the pockets which were measured were true pockets. The present study shows that there was an increase in the mean probing depth of the mandibular first molar after application of Blu Bite with a significant mean difference. Even though there was a significant increase in the probing depth, the magnitude of increase was just over a millimetre (Table 1 ) \& still very much within the normal probing depth of a clinically gingival sulcus in humans ( 2 to $3 \mathrm{~mm}$ ). ${ }^{17}$ The increase in probing depth might be due to gingival inflammation resulting in increase in pocket depth, which is commonly seen after the placement of orthodontic bands. ${ }^{18}$

The study also showed an increase in the mean pain score on percussion of mandibular first molars after bite-raising. The pain score increased slightly but it was still less than 2 (hurts little bit). Bite planes can sometimes cause pain as well as trauma to masticatory muscles and temporomandibular joints. ${ }^{19}$ It is not surprising to see some form of discomfort after placement of Blu Bite on the occlusal surface, but the amount of discomfort is very minimal and easily bearable by all the patients. Most patients have mentioned that they had mild to moderate discomfort on chewing in the first few days after placement of Blu Bite composite, but all of them got accustomed within a week's time \& the pain on chewing reduced to almost nil.

Orthodontic treatment can have mild adverse effects on periodontium after the treatment. ${ }^{13}$ There are studies which have shown experimentally as well as clinically that dental restorations with high points can induce periodontal changes like minor gingival alterations to pocket formation with bone loss and increase in tooth mobility. ${ }^{15}$ Usually the changes that occur in the periodontium will revert back to normal on removal of the excessive force. ${ }^{10,16}$ Thus it is believed that the changes (increase in the probing depth and pain score) which have occurred in the periodontium after temporary biteraising will also revert back to normal on its removal. During orthodontic treatment periodontium is susceptible to certain changes that happen due to the forces from the arch wire and brackets, this can also have an influence on the periodontium. ${ }^{18,20,21}$

Improper occlusal adjustment procedures resulting in faulty contact with forces not directed axially can cause further trauma. ${ }^{15}$ Periodontal trauma due to repeated mechanical forces on the periodontium which exceeds the physiologic limits of the tissue tolerance can result in breakdown of the supporting tissues of the tooth. Further reduction of periodontal support leads to pathological migration and further mutilation of occlusion. The amount of mutilation is influenced by severity, direction, duration, and frequency of occlusal forces. A previous study on animals showed that posterior bite blocks cause narrowing of periodontal ligament spaces and thinning of alveolar bone. ${ }^{22}$ Strength of the study is 
that, this is the first human study which investigated the effect of temporary bite-raiser on periodontium.

\section{CONCLUSIONS}

There was a mild yet significant increase in the probing depth and pain score on percussion after temporary bite-raising. Since these changes on periodontium are considered to be temporary, Blu Bite ${ }^{\mathrm{TM}}$ can be used as an alternative to fixed and removable posterior bite planes for bite opening during orthodontic treatment.

\section{Limitations}

This study did not investigate the long term effect on periodontium due to lack of fund and time. So, this also has to be taken into consideration while interpreting the results of this study. Further studies with this bite-raising method over a longer time frame with larger sample size should be conducted to evaluate its effects on dentition as well as on skeletal tissue structures.

Data sharing statement provided by the authors is available with the full text of this article at jemds.com.

Financial or other competing interests: None.

Disclosure forms provided by the authors are available with the full text of this article at jemds.com.

\section{REFERENCES}

[1] Roy AS, Singh GK, Tandon P, et al. An interim bite raiser. Int J Orthod Milwaukee 2013;24(2):63-4.

[2] Kravitz N, Jorgensen G, Frey S, et al. Resin bite turbos. J Clin Orthod 2018;52(9):456-61.

[3] Chachada A, Pedgaonkar S. A new posterior semi-fixed temporary bite raising appliance. Orthodontic Journal of Nepal 2020;10(1):73-4.

[4] Kessler M. The bite plate-an adjunct in periodontic and orthodontic therapy. J Periodontol 1980;51(3):123-35.

[5] Changsiripun C, Pativetpinyo D. Masticatory function after bite-raising with light-cured orthodontic band cement in healthy adults. Angle Orthod 2020;90(2):2638.

[6] Jackson S, Sandler PJ. Fixed biteplanes for treatment of deep bite. J Clin Orthod 1996;30(5):283-7.

[7] Vela-Hernández A, López-García R, García-Sanz V, et al. Nonsurgical treatment of skeletal anterior open bite in adult patients: posterior build-ups. Angle Orthod 2017;87(1):33-40.

[8] Vasilakos G, Koniaris A, Wolf M, et al. Early anterior crossbite correction through posterior bite opening: a 3D superimposition prospective cohort study. Eur J Orthod 2018;40(4):364-71.

[9] González CA, Sosa GO. Bilateral posterior telescopic crossbite correction through the use of Goshgarian palatal bar and bite turbos. Revista Mexicana de Ortodoncia 2016;4(2):e109-16.

[10] Pativetpinyo D, Supronsinchai W, Changsiripun C. Immediate effects of temporary bite-raising with lightcured orthodontic band cement on the electromyographic response of masticatory muscles. J Appl Oral Sci 2018;26:e20170214.

[11] Okeson JP. Occlusion and functional disorders of the masticatory system. Dent Clin North Am 1995;39(2):285300.

[12] Singh G, Gupta H, Rathi A, et al. The use of bite raisers in orthodontic treatment-a review of literature. Acta Scientific Dental Scienecs 2021;5(4):219-28.

[13] Gueray E. Temporary bite raiser. J Clin Orthod 1999;33(4):206-8.

[14] Hawker GA, Mian S, Kendzerska T, et al. Measures of adult pain: visual analog scale for pain (vas pain), numeric rating scale for pain (nrs pain), mcgill pain questionnaire (mpq), short-form mcgill pain questionnaire (sf-mpq), chronic pain grade scale (cpgs), short form-36 bodily pain scale (sf-36 bps) and measure of intermittent and constant osteoarthritis pain (icoap). Arthritis Care Res (Hoboken) 2011;63(S11):S240-52.

[15] Vickers ER, Cousins MJ, Woodhouse A. Pain description and severity of chronic orofacial pain conditions. Aust Dent J 1998;43(6):403-9.

[16] Narayan VK, Samuel SR. Appropriateness of various behavior rating scales used in pediatric dentistry: a review. Journal of Global Oral Health 2020;2(2):112-7.

[17] Newman MG, Takei H, Klokkevold PR, et al. Carranza's clinical periodontology. Elsevier Health Sciences 2011: p. 872.

[18] Alfuriji S, Alhazmi N, Alhamlan N, et al. The effect of orthodontic therapy on periodontal health: a review of the literature. Int J Dent 2014;2014:585048.

[19] Kharbanda OP. Orthodontics: diagnosis of \& management of malocclusion \& dentofacial deformities. Elsevier Health Sciences 2019: p. 1022.

[20] Newman MG, Takei H, Klokkevold PR, et al. Newman and Carranza's clinical periodontology. Elsevier Health Sciences 2018: p. 944.

[21] Orthodontics: diagnosis and management of malocclusion and dentofacial deformities. Vol. 230. $3^{\text {rd }}$ edn. India: Elsevier 2021:10-10.

[22] Denes BJ, Bresin A, Kiliaridis S. The influence of altered functional loading and posterior bite-blocks on the periodontal ligament space and alveolar bone thickness in rats. Acta Odontol Scand 2016;74(7):518-24. 